\title{
FITOSSANIDADE
}

\section{TEORES DE CA E VARIÁVEIS METEOROLÓGICAS: RELAÇÕES COM A INCIDÊNCIA DA MANCHA FISIOLÓGICA DO MAMÃO NO NORTE FLUMINENSE ${ }^{(1)}$}

\author{
ELIEMAR CAMPOSTRINI (2); HEBER CRUZ LIMA ${ }^{(2)}$; JURANDI GONÇALVES DE OLIVEIRA ${ }^{(2)}$; \\ PEDRO HENRIQUE MONNERAT ${ }^{(3)}$; CLÁUDIA SALES MARINHO ${ }^{(3)}$
}

\begin{abstract}
RESUMO
No Brasil e no mundo, o mamoeiro (Carica papaya L.) tem apresentado um distúrbio fisiológico no fruto denominado de Mancha Fisiológica do Mamão (MFM). Na literatura, pouco se conhece sobre as causas desta anomalia que afeta sensivelmente a comercialização dos frutos da espécie. Com o objetivo de se buscar informações relacionadas às causas da MFM, foi realizado um estudo, durante um ano, em um plantio comercial localizado em São Franscisco do Itabapoana (RJ), no norte fluminense. Foram feitas relações entre algumas variáveis do clima (temperatura, déficit de pressão de vapor, precipitação pluvial e radiação solar global) e os teores de Ca na planta [limbo, pecíolo, pedúnculo, epicarpo não-exposto (face do fruto próxima ao tronco) e epicarpo exposto (face do fruto oposta ao tronco)] com a incidência da MFM. Observou-se que a maior incidência de MFM foi durante setembro/2000. Em janeiro/2001, a incidência da MFM foi praticamente nula. A amplitude térmica, nos três meses que antecederam a setembro/2000, foi a variável do clima que mais se relacionou com a incidência da MFM. Em setembro, os teores de Ca em todas as partes do fruto (pedúnculo, epicarpo exposto e não-exposto) estudadas foram maiores. $\mathrm{Na}$ época que antecedeu o mês de setembro, as relações $\mathrm{Ca} / \mathrm{K}$ e Ca/Mg foram estatisticamente maiores no epicarpo exposto e não-exposto e, nesta época, a relação $\mathrm{Ca} / \mathrm{P}$ foi estatisticamente maior no pedúnculo e no epicarpo não-exposto. Os efeitos da amplitude térmica sobre a incidência da MFM são discutidos e a hipótese de que os teores baixos de Ca no fruto poderiam causar desestabilização na parede celular, o que facilitaria o extravasamento do látex e provocaria a MFM, deve ser reavaliada.
\end{abstract}

Palavras-chave: nutriente mineral, temperatura, amplitude térmica, mamoeiro, déficit de pressão de vapor do ar.

( $\left.{ }^{1}\right)$ Recebido para publicação em $1 .^{\circ}$ de março de 2005 e aceito em 15 de julho de 2005.

$\left({ }^{2}\right)$ Universidade Estadual do Norte Fluminense, Centro de Ciências e Tecnologias Agropecuárias, Laboratório de Melhoramento Genético Vegetal, Setor de Fisiologia Vegetal, Av. Alberto Lamego, 2000, 28015-620 Campos dos Goytacazes (RJ).

$\left(^{3}\right)$ Universidade Estadual do Norte Fluminense, Centro de Ciências e Tecnologias Agropecuárias, Laboratório de Fitotecnia, Setor de Nutrição Mineral de Plantas, Campos dos Goytacazes (RJ). 


\section{ABSTRACT \\ Ca CONCENTRATION AND METEOROLOGICAL VARIABLES: RELATIONSHIPS WITH SKIN FRECKLES IN PAPAYA (CARICA PAPAYA L.) FRUITS}

In Brazil and other parts of the world, papaya fruit suffer with a physiological disruption, known as skin freckles (SF). There is very little information available concerning the causes of this disruption that seriously affects the commercialization of the papaya fruit. In an attempt to discover the possible cause of SF, experiments were carried out during 12 months in a commercial plantation located in São Franscisco do Itabapoana, North of Rio de Janeiro State, Brazil, to measure the effect of climate on SF, such as air temperature, air vapor pressure deficit, rainfall and incoming solar radiation, as well as levels of $\mathrm{Ca}$ in the plants [blade, petiole, pedicel, epicarp (peel) not-exposed to sunlight (part of the fruit facing the stem) and the part o the fruit exposed to direct sunlight, related to the incidence of SF. A high incidence of SF was observed during the month of September 2000, however during the month of January 2001 no SF was detected. Thermal temperature during the three months before September was the variable that was most closely correlated to the incidence of SF. In September the levels of Ca in all parts of the fruit (exposed and non-exposed epicarp and pedicel) were higher than during other periods of evaluation. During the period before September, the ratios of $\mathrm{Ca}: \mathrm{K}$ and $\mathrm{Ca}: \mathrm{Mg}$ were higher in the exposed and nonexposed epicarp. Also at this time the ratio of $\mathrm{Ca}: \mathrm{P}$ were higher in the non-exposed epicarp and pedicel. The effect of thermal amplitude on the incidence of SF are discussed and the hypothesis that low levels of $\mathrm{Ca}$ in the fruit could destabilize the cell walls, facilitating leaking of latex, provoking the symptoms of SF, will be reevaluated.

Key words: mineral nutrient, air temperature, thermal amplitude, papaya, air vapor pressure deficit.

\section{INTRODUÇÃO}

No Brasil, o cultivo do mamoeiro está em expansão e, em 2003, destacaram-se como Estados produtores e exportadores, o Espírito Santo, com a exportação de $23.080 .532 \mathrm{~kg}$, a Bahia, com 2.482 .623 $\mathrm{kg}$ e o Rio Grande do Norte com $5.817 .045 \mathrm{~kg}$ (BRAPEX, 2004). Nesse período, foram exportados $32.811 .673 \mathrm{~kg}$, o que correspondeu ao valor obtido de US\$24.043.312 FOB (BRAPEX, 2004).

Em virtude da demanda criada pelo crescente consumo mundial, principalmente nos Estados Unidos, Canadá e países europeus como Alemanha, Portugal, Países Baixos e Reino Unido, o cultivo dessa espécie tem apresentado grandes perspectivas de crescimento (BRAPEX, 2004). Conseqüentemente, esse fato tem ocasionado um aumento na área de cultivo desta espécie no Brasil. No Estado do Rio de Janeiro, esse quadro se repete, principalmente na Região Norte Fluminense. Nessa região, devido à sua posição geográfica, a qual se localiza próxima ao Estado do Espírito Santo e à cidade do Rio de Janeiro (grande centro consumidor e capacidade portuária para exportação), observam-se ótimas condições para o cultivo dessa espécie. Outro fator que proporciona uma vantagem para a região é o clima favorável à fruticultura tropical.

No entanto, tanto no Brasil como em outras partes do mundo, tem-se constatado alguns problemas na cultura, entre os quais pode-se citar a "Mancha
Fisiológica do Mamão" (MFM). Na literatura, a MFM é conhecida e foi relatada a partir da década de cinqüenta. No Havaí, foi constatada por IsHII e Holzmann (1963) e Hine et al. (1965). Na África do Sul foi relatada por Le Roux (1950), citada por KAISER et al. (1996). Em alguns trabalhos notam-se tentativas de resolver o problema por meio de melhoramento genético (CHAN e ToH, 1988). No Brasil, a incidência desse distúrbio fisiológico foi observada em variedades e híbridos mais utilizados comercialmente, sendo uma anomalia que há vários anos ocorre com certa intensidade, em quase todos os países que possuem produção expressiva desse fruto. Na literatura, os relatos sugerem tratar-se de um distúrbio fisiológico, que normalmente ocorre nos meses mais frios/secos do ano causando sérios prejuízos à cultura (KAISER et al, 1996). Esses prejuízos se referem à desvalorização comercial do fruto, no aspecto estético.

Pelos estudos, as manchas que cobrem a epiderme são como placas de cera distribuídas sobre essa epiderme e estão relacionadas com os estômatos (Reys e PAull, 1994). Essas manchas são derivadas provavelmente do látex, já que os vasos laticíferos, que se estendem entre as células da epiderme e a superfície do fruto, parecem conter material semelhante ao exsudado na MFM (CoutinHo et al., 2001; KAISER et al., 1996). Pelas análises de proteína do material presente nas manchas, constata-se que essas proteínas são semelhantes, em termos de peso molecular, às proteínas do látex (KAISER et al., 1996). A possibilidade 
de que a temperatura elevada induz a exsudação do látex é sustentada pela suposição de que a flutuação na temperatura diária resultaria em uma variação da turgescência das células (Downton, 1981). A elevação na pressão de turgescência é esperada sob grandes flutuações diárias na temperatura. O látex exsudado sobre a subsuperfície do fruto pode desidratar as células em torno da exsudação, formando-se desse modo, tamanhos diferentes de "manchas", as quais foram associadas ao volume de látex exsudado (REYES e Paull, 1994; Saure, 2005).

Observam-se nos frutos inúmeras desordens fisiológicas associadas à deficiência nutricional, principalmente às relacionadas ao cálcio (MARSCHNER, 1995). Ainda, interações entre as relações nos teores de nutrientes podem causar distúrbios fisiológicos em folhas de algodoeiro (For et al, 1981) e feijão (Horst e MARSCHNER, 1978). Desse modo, os postulados de que deficiências nutricionais podem ser a causa da incidência da "Mancha Fisiológica do Mamão" não devem ser descartados.

Dentre os nutrientes minerais, o cálcio merece atenção especial no estudo da Mancha Fisiológica do Mamão, já que está relacionado com muitas desordens fisiológicas que atingem tanto os órgãos de armazenamento como frutos, raízes e folhas. Na literatura, uma excelente revisão sobre a translocação de cálcio nos frutos e os mecanismos de controle endógeno desse nutriente mineral nesses órgãos foi feita por SAURE (2005).

A importância desse nutriente no tecido vegetal está relacionada à ligação do Ca como pectato na lamela média, o qual é essencial para estruturação da parede celular e do tecido vegetal como um todo (MArschner, 1995). Segundo esse mesmo autor, a proporção de pectato de Ca na parede celular está relacionada com a suscetibilidade ao ataque de fungos e bactérias e com o amadurecimento de frutos.

Em diversos trabalhos, os autores constataram que, nos frutos, a ausência ou deficiência no influxo de $\mathrm{Ca}$ está relacionada às desordens fisiológicas (SAURE, 2005). Nesses órgãos, os aumentos nos teores deste nutriente mineral retardaram o fenômeno denominado "amaciamento" no mamoeiro (QIU et al, 1995) e mantiveram a qualidade dos frutos de maçã (Coway e Sams, 1987; Poovaiah, 1986), tomate (Rigney e WiLLs, 1981), abacate (EAKS, 1985) e manga (SCHAFFER et al, 1994). Desordens fisiológicas associadas com teores inadequados de cálcio ocorrem em várias plantas (BANGERTH, 1979).

A relação entre a absorção de Ca e os fatores climáticos foram relacionados por CLARKSON (1984) e bem discutidos por SAURE (2005). Em manga, vários relatos sugerem que os fatores edáficos e do ambiente têm sido relacionados ao desenvolvimento de desordens fisiológicas (SCHAFFER et al, 1994). Em adição aos fatores edáficos, as variáveis do ambiente como umidade relativa e temperatura do ar têm estado envolvidas no desenvolvimento das desordens fisiológicas em manga e podem ser indiretamente um dos fatores de deficiência de Ca no fruto. Em alta umidade relativa, alguns autores observaram teor reduzido de Ca nas folhas superiores e elevação no teor deste nutriente mineral nos frutos de tomateiro (CHor et al, 1997; Mulholland et al, 2001). Contudo, em frutos de Capsicum annumm L., a umidade relativa alta reduziu o acúmulo de Ca nos frutos (TADESSE et al, 2001). Entretanto, apesar dessas informações, segundo Saure (2005), existe muita controvérsia na literatura e pouco se conhece sobre os efeitos da umidade relativa e da temperatura nos teores de $\mathrm{Ca}$ nos frutos.

O objetivo deste trabalho foi estabelecer possíveis relações entre os teores de macronutrientes minerais, as variáveis meteorológicas e a ocorrência da "Mancha Fisiológica do Mamão" em plantas de Carica papaya L., cultivadas sob condição de campo no Norte do Estado do Rio de Janeiro.

\section{MATERIAL E MÉTODOS}

\subsection{Material vegetal e condições de cultivo}

O experimento foi realizado em plantio comercial localizado no município de São Francisco de Itabapoana (RJ), a cerca de $60 \mathrm{~km}$ da cidade de Campos dos Goytacazes (RJ), latitude $21^{\circ} 27^{\prime} \mathrm{S}$, longitude $41^{\circ} 15^{\prime} \mathrm{O}$ e altitude $12 \mathrm{~m}$. Para tanto, foram utilizadas plantas de mamoeiro (Carica papaya L.) do grupo "Formosa", com idade inicial de 19 meses, sendo o espaçamento adotado de $3,8 \times 2,0 \mathrm{~m}$ e o solo do tipo Argissolo Amarelo. A lavoura foi irrigada pelo sistema do tipo pivô central, não havendo turno de rega definido. Esse manejo foi adotado pelo produtor para a produção comercial de frutos.

\subsection{Análise nutricional}

Foram analisados os teores de nitrogênio orgânico, fósforo, potássio, cálcio, magnésio e enxofre em folhas e em frutos do mamoeiro. A partir dos teores dos nutrientes minerais relatados, foram determinadas as relações $\mathrm{Ca} / \mathrm{N}, \mathrm{Ca} / \mathrm{P}, \mathrm{Ca} / \mathrm{K}, \mathrm{Ca} / \mathrm{Mg}$ e $\mathrm{Ca} / \mathrm{S}$. 
As avaliações foram efetuadas no Setor de Fisiologia Vegetal e no Laboratório de Nutrição Mineral de Plantas, do Centro de Ciências e Tecnologias Agropecuárias, da Universidade Estadual do Norte Fluminense. O experimento foi desenvolvido durante o período de um ano tendo sido realizadas avaliações nutricionais em dez plantas, em duas épocas distintas. A primeira época, considerada época de alta incidência da MFM, correspondeu às colheitas dos frutos em setembro de 2000, e, a segunda época, com baixa incidência do distúrbio, referiu-se às colheitas efetuadas em janeiro de 2001. Na região do solo próximo a cada planta $( \pm 30 \mathrm{~cm})$ e em cada época, foram feitas as análises químicas do solo nas profundidades de 0 a $20 \mathrm{~cm}$ e 20 a $40 \mathrm{~cm}$.

Em cada planta e em cada época, foram analisados o limbo foliar, pecíolo, epicarpo nãoexposto (face do fruto próxima ao tronco), epicarpo exposto (face do fruto que recebeu a radiação solar) e o pedúnculo.

A folha coletada para análise dos nutrientes minerais foi a recém-madura, caracterizada por apresentar uma flor recém-aberta localizada na axila. A coleta das folhas foi efetuada antes das onze horas da manhã, sendo as mesmas divididas em limbo e pecíolo que foram imediatamente acondicionados em sacos plásticos, devidamente identificados.

Trinta frutos foram coletados quando estavam com cerca de quatro faixas amarelas na parte distal. Para a separação do epicarpo do fruto foram retirados pedaços deste órgão ( $\approx 50 \mathrm{~g})$, com auxílio de um furador de rolhas. Nesses pedaços, o epicarpo foi separado do mesocarpo (polpa), por meio de um estilete desinfetado. A espessura do epicarpo foi de aproximadamente $2 \mathrm{~mm}$. O pedúnculo, o epicarpo, o limbo e o pecíolo, após pesagem, foram levados para secagem em estufa de circulação forçada de ar, à temperatura de $70{ }^{\circ} \mathrm{C}$ por 48 horas. O material foi pesado novamente e então triturado em moinho (tipo Wiley) com peneira de 20 "mesh". A matéria seca, assim obtida, foi submetida às análises químicas.

As análises foram realizadas de acordo com métodos descritos por MALAVOLTA et al. (1989) e JonES JR. et al. (1991). O nitrogênio foi determinado pelo método de Nessler (JACKSON, 1958), após digestão da matéria seca com $\mathrm{H}_{2} \mathrm{SO}_{4}$ e $\mathrm{H}_{2} \mathrm{O}_{2}$. Fósforo, potássio, cálcio, magnésio e enxofre foram determinados no extrato obtido a partir da digestão com ácido nítrico e ácido perclórico. Utilizou-se o método colorimétrico do molibdato para a quantificação do fósforo, a espectrofotometria de emissão de chama para o potássio, turbidimetria para o enxofre e espectrofotometria de absorção atômica para os demais nutrientes.
Realizou-se teste t a 5\% de probabilidade para comparar os teores e relações nas mesmas partes da planta em épocas distintas. O mesmo teste, no mesmo nível de probabilidade, foi aplicado para comparar os teores nas mesmas épocas em partes diferentes da planta.

\subsection{Quantificação da "mancha fisiológica do mamão"}

Durante o período de um ano e a cada quinze dias foi efetuada a quantificação da mancha fisiológica. Para tanto, foi utilizada uma tela transparente (tipo folha de transparência para retroprojetor) de $75 \times 75 \mathrm{~mm}$ contendo 900 quadrículas de $6,25 \mathrm{~mm}^{2}$ cada uma. Em média, a área da tela correspondia entre $6 \%$ a $10 \%$ da área total do fruto do mamoeiro 'Formosa', e foi centralizada em um ponto distante $10 \mathrm{~cm}$ da parte distal do epicarpo exposto à incidência solar direta, sendo feita a contagem do número de quadrículas ocupadas pela mancha fisiológica. Após a contagem do número de quadrículas, foram calculadas as freqüências acumuladas com base na seguinte equação:

$\mathrm{F}=\mathrm{m} /(\mathrm{n}+1)$

Em que: $\mathrm{F}=$ Freqüência; $\mathrm{m}=$ Número de ordem; $\mathrm{n}=$ Número de dados.

\subsection{Variáveis meteorológicas}

Durante o período de estudo, foram monitoradas diariamente as variáveis meteorológicas como temperatura e umidade relativa do ar, precipitação pluvial e radiação solar global, por meio de uma estação climatológica Zeiss, Alemanha, localizada na Estação Experimental da Empresa de Pesquisa Agropecuária do Estado do Rio de Janeiro, PESAGRO (21 $\left.27^{\circ} \mathrm{S} ; 41^{\circ} 15^{\prime} \mathrm{O}\right)$, situada a $30 \mathrm{~km}$ do experimento. Com os valores diários das variáveis meteorológicas estudadas, foi obtida a média semanal e, dessa maneira, foram confeccionados os gráficos. A partir dos valores da temperatura e da umidade relativa do ar, e utilizando a equação proposta por Jones (1982), foi possível determinar o déficit de pressão de vapor do ar $(\mathrm{kPa})$.

DPV $=0,611375 \mathrm{e}^{\mathrm{t} *}[1-(\mathrm{UR} / 100)]$

$\mathrm{t}=\left[17,502^{*}\left(\mathrm{~T}_{\mathrm{ar}}\right)\right] /\left[240,97+\mathrm{T}_{\mathrm{ar}}\right]$

Em que:

$\mathrm{UR}=$ umidade relativa do ar (\%)

$\mathrm{T}_{\mathrm{ar}}=$ temperatura do $\operatorname{ar}\left({ }^{\circ} \mathrm{C}\right)$ 


\section{RESULTADOS E DISCUSSÃO}

No período de um ano e com a contagem da incidência da MFM efetuada a cada 15 dias, não se observou incidência da MFM nos frutos do grupo 'Formosa' colhidos em janeiro de 2001 (Figura 1). Entretanto, os frutos colhidos em setembro/2000 estavam com freqüência máxima acumulada de $1 \mathrm{com}$ 150 quadrículas preenchidas com a MFM. No quadro de contagem, esse valor de 150 representa uma área ocupada pela MFM de $938 \mathrm{~mm}^{2}$. Essa área corresponde a aproximadamente $17 \%$ da área total amostrada $\left(5.625 \mathrm{~mm}^{2}\right)$. De fato, em setembro/2000, a incidência da MFM causou elevado comprometimento no aspecto estético externo do epicarpo exposto dos frutos (dados não apresentados).

Segundo KAISER et al. (1996), na África do Sul, a MFM, conhecida em inglês como skin freckles, ocorre predominantemente nos frutos que se desenvolvem em períodos de temperaturas baixas do ar. Nesse experimento, localizado no Norte Fluminense, a incidência desse distúrbio fisiológico revelou uma similaridade de ocorrência com os relatos de KAISER et al. (1996). Em plantios comerciais de mamoeiro no Sudoeste da Bahia, informações semelhantes foram relatadas por UENo et al. (2002). Segundo esses autores, nessa região, a MFM ocorreu com maior incidência em agosto.
No Havaí, em trabalho com mamoeiro do grupo Solo cv. 'Sunset', Reyes e PAull (1994) verificaram que houve uma correlação negativa entre incidência da MFM (IM) e o diâmetro das manchas (D) com as variáveis climáticas (temperaturas máximas e mínimas do ar). Os valores observados dos coeficientes de correlação foram -0,87 (IM), -0,70 (D) e -0,78 (IM), -0,67 (D) para as temperaturas máxima e mínima, respectivamente. A maior correlação obtida foi durante dois meses antes da colheita dos frutos. Segundo Selvaraj et al. (1982), no Hawai, nesse período, ocorre o maior acúmulo de matéria seca dos frutos.

Neste trabalho no Norte Fluminense, em setembro/2000, que correspondeu à época de maior incidência da MFM (Figura 1), houve uma similaridade com os resultados obtidos por REYES e Paull (1994). De fato, nos três meses anteriores (junho, julho e agosto/2000) ao mês de maior incidência, ocorreram temperaturas do ar máximas e mínimas inferiores aos três meses (outubro, novembro e dezembro/2000) que antecederam o mês de incidência nula da MFM (Figura 2).

Na Figura 3, observa-se o gráfico referente à amplitude térmica. Verifica-se que as maiores amplitudes ocorreram nos três meses que antecederam o mês em que os frutos do mamoeiro estavam com maior incidência da MFM. Assim como no trabalho publicado por REYES e PAULL (1994), as temperaturas baixas do ar contribuíram para a ocorrência da MFM.
Setembro/2000

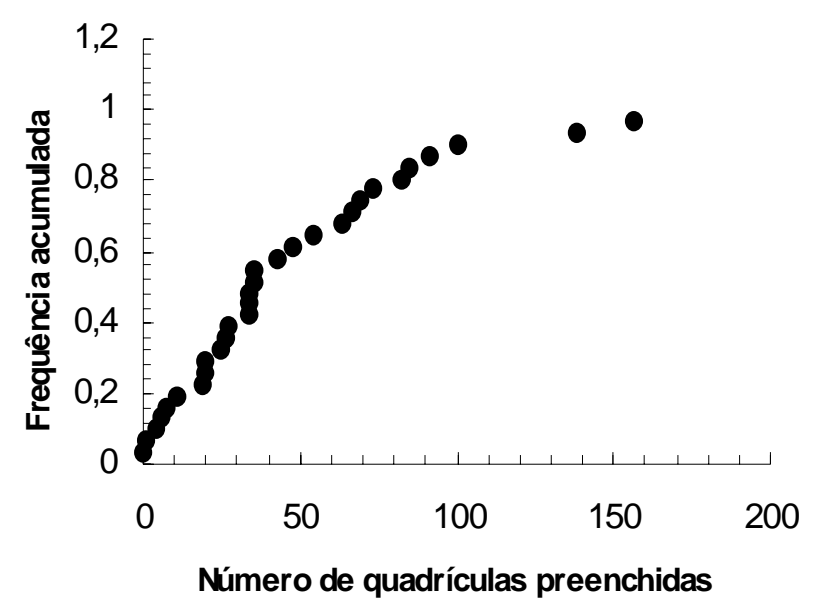

Janeiro/2001

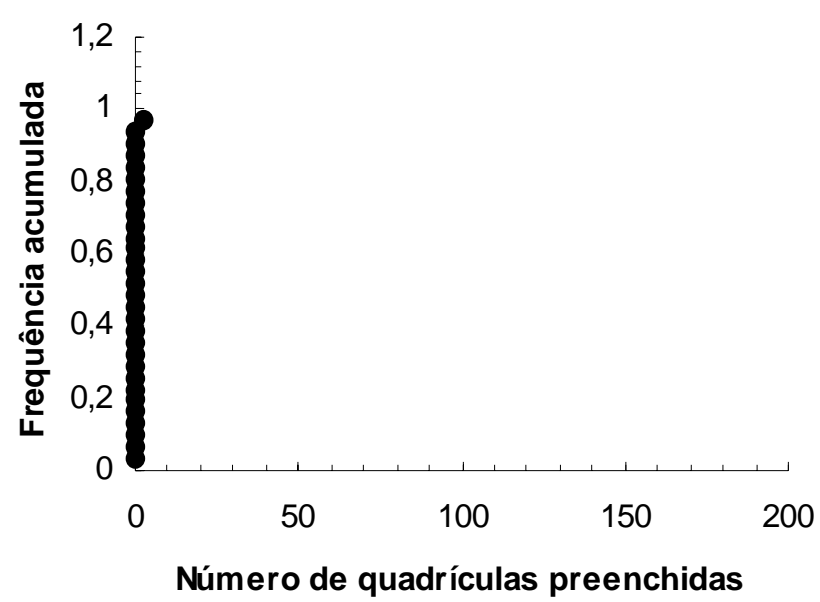

Figura 1. Curva de incidência da mancha fisiológica do mamão (MFM), em duas épocas, em plantio comercial no município de São Francisco do Itabapoana (RJ). O eixo x se refere ao número de quadrículas preenchidas com a MFM, em um quadrado desenhado em folha transparente de 900 quadrículas de $6,25 \mathrm{~mm}^{2}$ cada. O eixo y se refere à freqüência acumulada dos respectivos números das manchas presentes no quadro de contagem. 


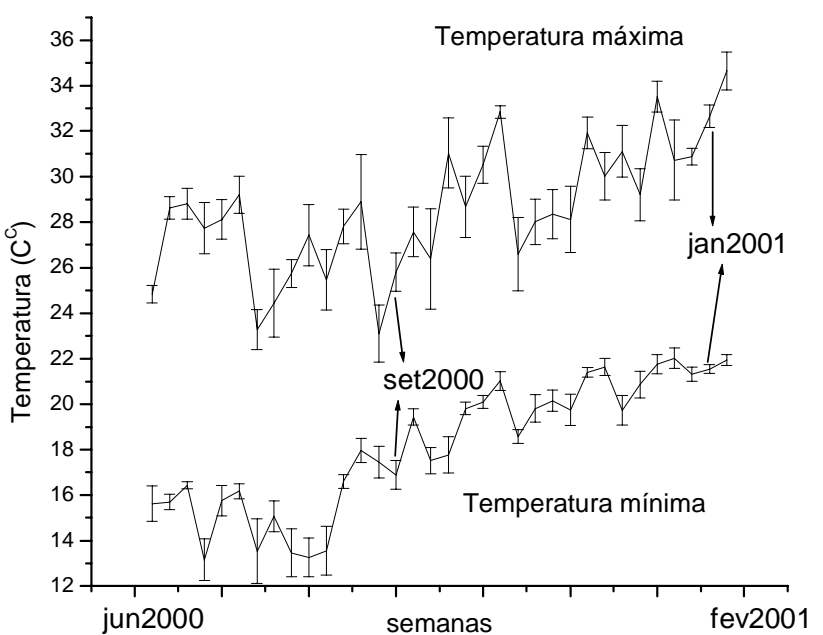

Figura 2. Médias semanais das temperaturas máximas e mínimas do ar obtidas na estação climatológica. As barras verticais representam o desvio-padrão.

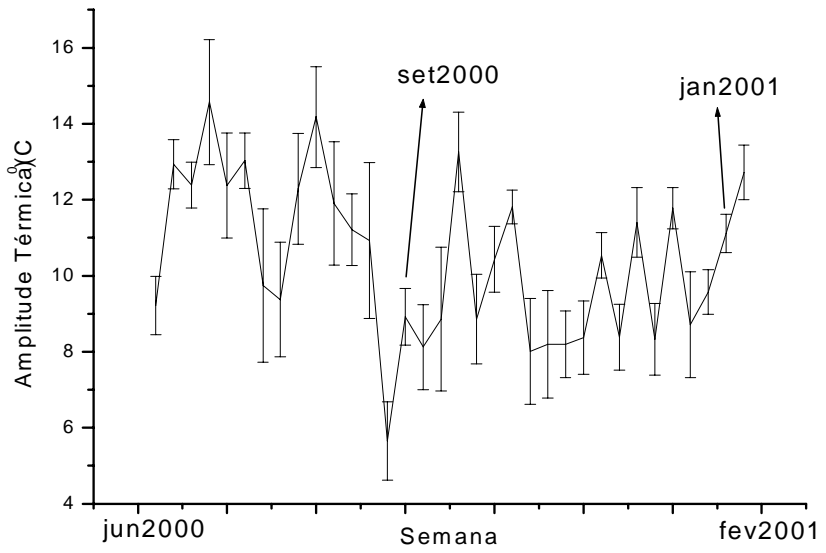

Figura 3. Médias semanais da amplitude térmica obtidas na estação climatológica. As barras verticais representam o desvio-padrão.

critério científico rigoroso, possivelmente, nos meses com baixas precipitações pluviais em associações com as elevadas amplitudes térmicas, o tecido do mamoeiro em estudo poderia ter apresentado elevadas flutuações hídricas. De fato, num amplo estudo sobre a MFM, no Oeste da Bahia, Ueno et al. (2002) relataram que a incidência da MFM foi maior nos plantios onde o manejo da irrigação era deficitário. Em contradição, pelos resultados apresentados por ReYes e PAULL (1994), não houve correlação entre a incidência da MFM com a precipitação pluvial. Entretanto, nesse trabalho de Reyes e PAull (1994), houve uma correlação positiva $(0,68)$ entre o diâmetro da MFM e a precipitação pluvial dois meses antes da colheita. Contudo, em estudo realizado durante um ano, na mesma região em que se desenvolveu este experimento, ReIS et al (2003) relataram que a incidência elevada da MFM, de julho a setembro, foi associada à elevada tensão de água no solo (-114 kPa) nos quatro meses que antecederam esse período com alta incidência da MFM.

É necessário desenvolver maior quantidade de trabalhos em Carica papaya, objetivando avaliar os efeitos da temperatura e/ou amplitude térmica, em associação às flutuações hídricas da planta sobre a pressão de turgescência dos vasos laticíferos, para se definir melhor ação dos tais fatores sobre a incidência da MFM.

Torna-se importante relatar que não somente os valores da temperatura per si podem ser importantes para a ocorrência da MFM, mas também a amplitude térmica pode ser um fator a ser discutido. 
Indiretamente, essa variável climática, provavelmente, cause variações bruscas na turgescência dos tecidos vegetais. Este fato é observado pelo efeito direto desta variável sobre a pressão de vapor do ar. Amplitudes térmicas elevadas podem causar variações bruscas no déficit de pressão de vapor (DPV). Em frutos de pimentão, a elevada umidade relativa do ar (DPV baixo), causada pela baixa temperatura no período noturno, provocou limitações na transpiração do fruto (Aloni et al., 1998). Segundo estes autores, a limitação no processo transpiratório causou significativas rachaduras em frutos da espécie em estudo. Na região do Oeste da Bahia, segundo UENO et al. (2002), durante o período crítico de incidência da MFM, verificou-se maior amplitude térmica diária. Entretanto, segundo GrANGE e HAND (1987), a umidade do ar avaliada pelo $\mathrm{DPV}$, variando de 1,0 a $0,2 \mathrm{kPa}\left(55\right.$ a $90 \%$ a $\left.20{ }^{\circ} \mathrm{C}\right)$, tem pouco efeito sobre os processos fisiológicos e de desenvolvimento de espécies hortícolas. Na figura 5, os valores médios semanais do DPV variaram de 0,3 a 1,1 kPa. Com base nas informações dos autores supracitados, este fato pode revelar que esta variável climática do ar pode ter tido pouca influência sobre a incidência da MFM neste experimento no Norte Fluminense. Os valores elevados de DPV foram causados pelas temperaturas elevadas nos três meses que antecederam ao período de menor incidência da MFM (Figura 2).

GRANGE e HAND (1987) relataram que os efeitos do DPV, sobre o processo fisiológico da planta, podem estar atuando sobre a taxa fotossintética líquida (via efeitos sobre a abertura e fechamento dos estômatos); no crescimento e desenvolvimento (por meio do estado hídrico do tecido); sobre distúrbios fisiológicos relacionados à absorção/translocação do Ca; na incidência de doenças e sobre a sensibilidade aos gases poluentes.

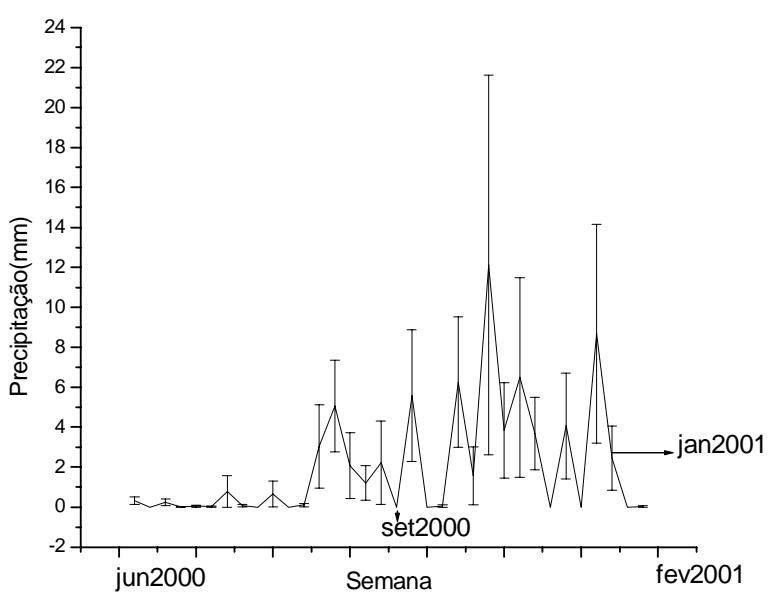

Figura 4. Totais semanais da precipitação pluviométrica obtidas pela estação climatológica. As barras verticais representam o desvio-padrão.
Uma associação que pode ser efetuada é a relação entre DPV e o teor de Ca no tecido vegetal. Uma vez que este nutriente é translocado exclusivamente no xilema, a quantidade de Ca num órgão vegetal é diretamente relacionada ao fluxo de água através do xilema (GRANGE e HAND, 1987). Dessa maneira, em um determinado local da planta, a deficiência deste nutriente ocorre devido à restrição ao fluxo de água influenciado pela umidade neste local ou pela umidade em torno da planta (GRANGE e HAND, 1987). Segundo Marschner (1995), em dicotiledôneas esse processo é mais importante, pois nestas classes de plantas a capacidade de troca de cátions no apoplasto é maior. No presente trabalho, entre as épocas estudadas não houve diferenças significativas no teor de Ca no limbo e no pecíolo das folhas de mamoeiro (Figura 7), embora nos três meses que antecederam ao mês de incidência nula da MFM (janeiro/2001), os valores da radiação solar e do DPV foram maiores (Figuras 5 e 6 ).

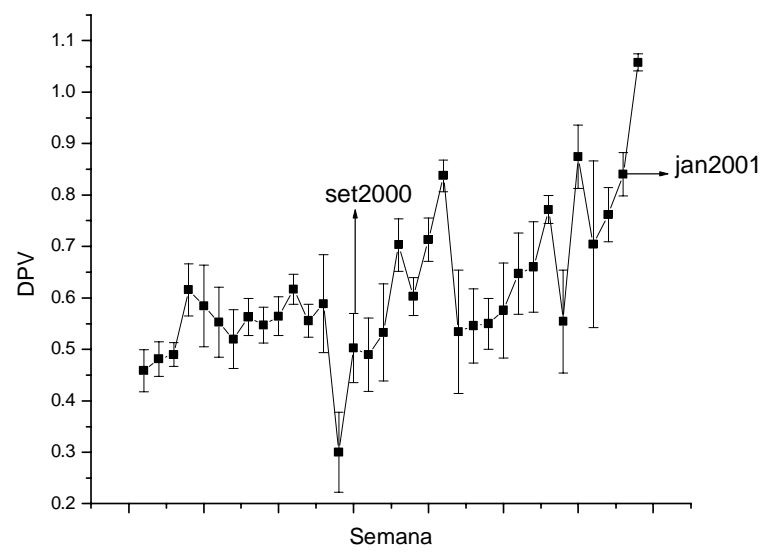

Figura 5. Médias semanais do déficit de pressão de vapor de ar (DPV, kPa) obtidas na estação climatológica. As barras verticais representam o desvio-padrão.

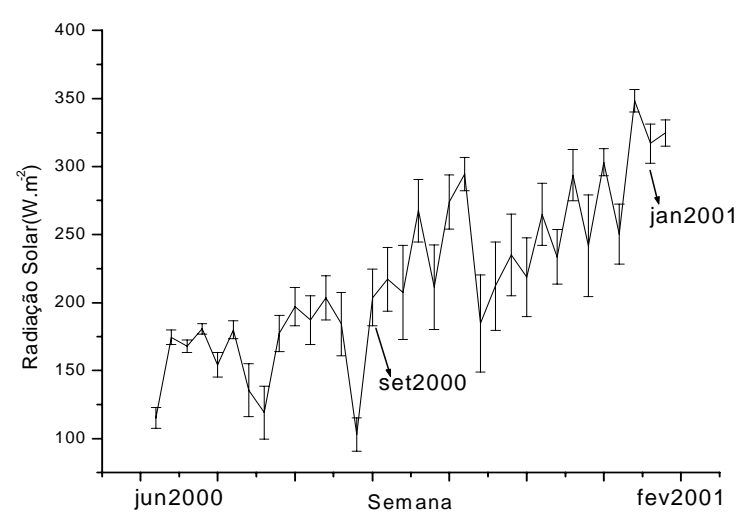

Figura 6. Médias semanais da radiação solar global obtidas na estação climatológica. As barras verticais representam o desvio-padrão. 
Apesar de os teores do Ca no solo não tenham apresentado diferenças entre as épocas amostradas (dados não-apresentados), era esperado que os teores de Ca na folha das plantas de mamoeiro fossem maiores no mês de janeiro/2001, uma vez que os valores da radiação solar e DPV foram também maiores nos três meses anteriores a janeiro/2001 (Figuras 5 e 6). Entretanto, nessa época, os valores elevados dessas variáveis poderiam ter causado maiores taxas de crescimento, resultando assim, um possível efeito de diluição do Ca.

Segundo Costa (1995), em mamoeiros cultivados em plantio comercial, no Estado do Espírito Santo, foram encontrados no limbo teores de Ca de 18,7 na época das águas e $25,3 \mathrm{~g} \mathrm{~kg}^{-1}$ na época da seca. Em adição, no pecíolo, ReUtHer e Robinson (1986) verificaram teores de 10 a $25 \mathrm{~g} \mathrm{~kg}^{-1}$. Entretanto, MARinho (1999) trabalhando com os híbridos 'Tainung 1', 'Tainung 2' e 'Know You', todos do grupo Formosa, constatou teores médios para o limbo de $13,4 \mathrm{~g} \mathrm{~kg}^{-1}$ e para o pecíolo de $13,3 \mathrm{~g} \mathrm{~kg}^{-1}$. Esse fato mostra que os teores desse nutriente mineral, nas plantas cultivadas no Norte Fluminense, estavam próximos aos observados pelos autores supracitados.

No fruto, nos teores de $\mathrm{Ca}$, ocorreram diferenças entre as épocas amostradas (Figura 8). Os frutos colhidos em janeiro/2001 estavam com teores desse nutriente reduzidos em relação a setembro/ 2000. Esse fato revela que menores teores de Ca no fruto não indicam uma relação com a incidência da MFM. A hipótese de que baixos teores de Ca poderiam não ser suficientes para a estabilização da parede celular e integridade de membranas, o que facilitaria o extravasamento do látex, deve ser reavaliada, considerando-se que um excesso desse nutriente pode ocasionar uma maior rigidez às paredes das células, conseqüentemente menor elasticidade, tornando-as mais predispostas ao rompimento, quando ocorre uma elevação na pressão de turgescência. Estudos mais detalhados a esse respeito deverão ser realizados.

A competição do $\mathrm{Ca}$ entre os drenos é intensificada quando a concentração desse nutriente no xilema é baixa, e o processo transpiratório é elevado. Sendo assim, um contínuo suprimento de Ca é requerido para o desenvolvimento normal do fruto, uma vez que pouca ou nenhuma redistribuição desse elemento é verificada para o crescimento dos drenos (Poovaiah, 1985). Geralmente, tecidos vegetais com elevadas taxas transpiratórias acumulam maiores teores de Ca. As folhas acumulam maiores conteúdos desse nutriente do que os frutos. De fato, neste trabalho foi observado teores mais elevados nas folhas do que nos frutos (Figuras 7 e 8).

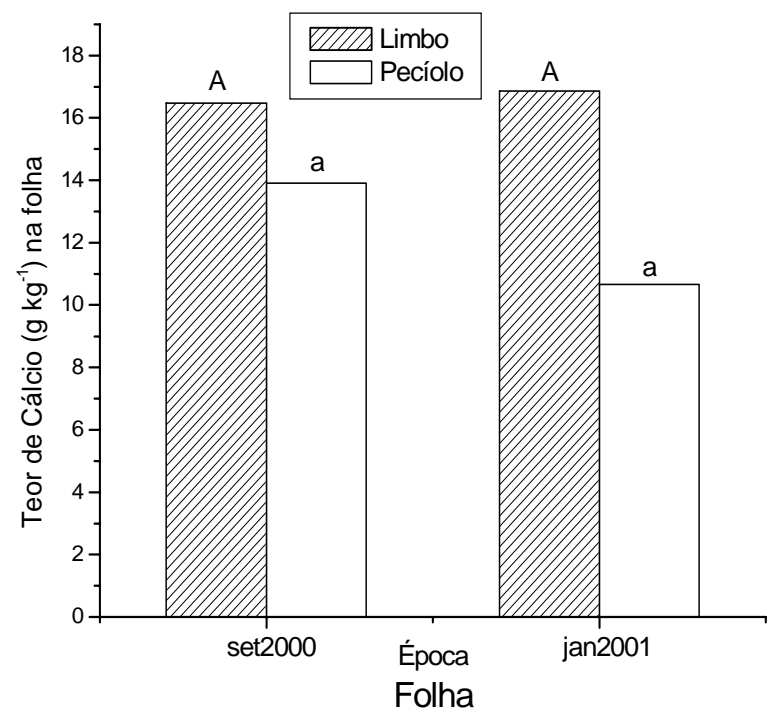

Figura 7. Teores de Ca nas folhas de plantas de mamoeiro cultivadas em condição de campo em duas épocas (setembro/maior incidência da MFM e janeiro/ incidência nula) em São Francisco do Itabapoana, RJ. $(\mathrm{n}=10$ plantas). Médias seguidas de mesma letra e mesmo número não diferem estatisticamente a $5 \%$ pelo teste $t$.

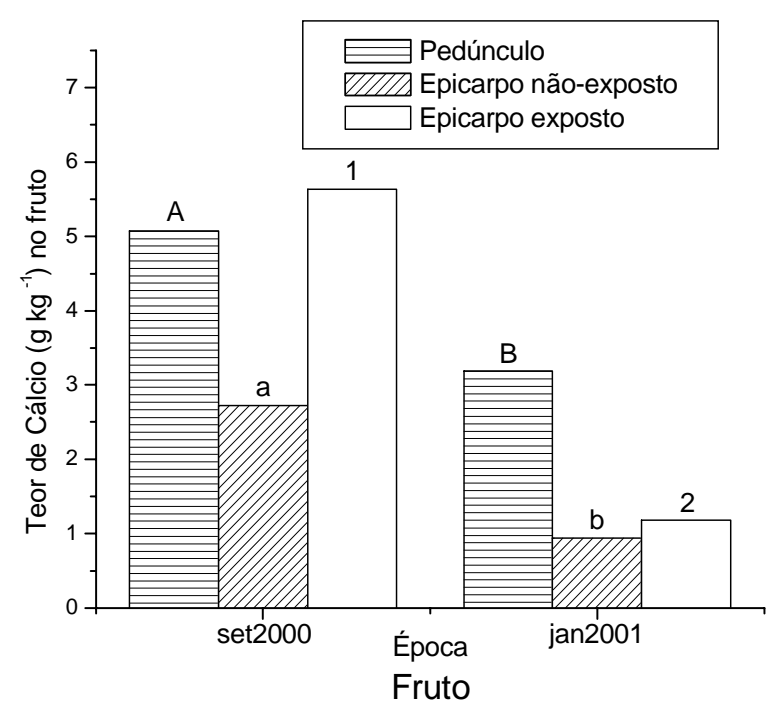

Figura 8. Teores de Ca nos frutos de plantas de mamoeiro cultivadas em condição de campo em duas épocas (setembro/maior incidência da MFM e janeiro/ incidência nula) em São Francisco do Itabapoana, RJ. $(\mathrm{n}=10$ plantas). Médias seguidas de mesma letra e mesmo número não diferem estatisticamente a $5 \%$ pelo teste t. Números diferentes entre as análises do epicarpo exposto diferem estatisticamente a $5 \%$ pelo teste $t$. 
$\mathrm{O}$ aumento de $\mathrm{Ca}$, na solução do solo, pode resultar em aumento desse teor nas folhas, mas não necessariamente em órgãos como frutos e tubérculos. Nesses órgãos, o suprimento de tal nutriente mineral é predominantemente via floema (MARSCHNER, 1995). As plantas têm desenvolvido mecanismos para restringir o transporte de Ca nesses órgãos por meio da manutenção de baixas concentrações na seiva do floema, pela precipitação desse nutriente como oxalato nos elementos crivados (FINK, 1991), ou mantendo o Ca na semente (Mix e MARSCHNER, 1976). A diluição no teor desse nutriente pelo crescimento é outra forma de manter o nível de Ca baixo nos tecidos vegetais.

Em frutos com elevadas taxas de crescimento (alta divisão e expansão celular), as possibilidades de decréscimos acentuados nos níveis de Ca são maiores, uma vez que estes órgãos vegetais têm reduzidas taxas transpiratórias. Nessas condições, os níveis baixos de Ca não são suficientes para a estabilização das paredes celulares e integridade das membranas (Marschner, 1995), podendo ocasionar distúrbios fisiológicos. Dessa maneira, possivelmente, em janeiro/2001, os valores baixos dos teores de Ca e suas alterações nas relações com outros nutrientes $(\mathrm{P}$, $\mathrm{K}, \mathrm{Mg}$ e S), nas partes dos frutos de mamoeiro, podem ser explicados pela elevada taxa transpiratória das folhas, em detrimento ao movimento de água e, conseqüentemente, do Ca para o fruto. Ainda, o baixo valor de Ca nesses órgãos estaria relacionado com o maior efeito de diluição no teor desse nutriente, causada pela elevada taxa de crescimento do fruto. Em setembro/2000, nos frutos, em associação com as menores taxas de crescimento proporcionadas pela menor temperatura do ar durante o desenvolvimento desses órgãos (Figura 2), o efeito da diluição do teor de $\mathrm{Ca}$ foi de menor intensidade, explicando assim o maior teor deste nutriente no fruto.

Em macieira, comparadas com as plantas de moderado crescimento vegetativo, notou-se, nas plantas com excessivo lançamento de ramos e folhas, teor reduzido de Ca no fruto (GREene e LoRD, 1983; Greene, 1991). Segundo esses autores, se essa fase de elevado lançamento foliar coincidir com a de maior crescimento dos frutos, o teor baixo de Ca nesses órgãos é devido à intensa competição por esse nutriente, entre os frutos e os ramos vigorosos.

Outro fato importante que fortalece a relação negativa entre os teores de Ca nos tecidos vegetais e a incidência da MFM foi o maior teor de Ca no epicarpo exposto em relação ao epicarpo não exposto (Figura 8). Em mamoeiro do grupo 'Formosa', verificou-se que a incidência da MFM é maior na face do fruto que recebeu radiação solar direta (epicarpo exposto) (dados não apresentados). A possível justificativa para os teores de Ca serem maiores nessa parte do epicarpo, é que nessa face, em relação ao epicarpo não-exposto, pode ocorrer uma taxa transpiratória maior. De fato, a densidade estomática, do epicarpo de frutos de mamão, é em média de 2.340 estômatos $\mathrm{cm}^{-2}$ (PAull e CHen, 1989), o que pode mostrar uma transpiração nesses órgãos. Dessa maneira, como o epicarpo externo está mais suscetível às ações do DPV, esse fato pode ser justificável.

Em setembro, a diferença entre os teores no epicarpo exposto e no epicarpo não-exposto foi maior em relação a janeiro/2001 (Figura 9). Como foi relatado anteriormente, esse resultado pode ser explicado pela maior transpiração das folhas em relação aos frutos, no mês de janeiro/2001. Nessa época, sendo as folhas um forte dreno ao movimento de $\mathrm{Ca}$, a quantidade deste nutriente ficaria reduzida no fruto e as diferenças não seriam evidentes. Tornase importante realizar mais experimentos com o mamoeiro, objetivando estudar as possíveis relações do padrão de distribuição do Ca entre os diferentes órgãos da planta com a taxa transpiratória.

Sobre as relações entre o $\mathrm{Ca}$ e os demais nutrientes estudados, observa-se nas figuras 11 e 12, que as relações $\mathrm{Ca} / \mathrm{Ke} \mathrm{Ca} / \mathrm{Mg}$ nos frutos revelaram um comportamento semelhante ao teor de Ca (Figuras 7 e 8). Embora os teores de $\mathrm{Mg}$, nas partes dos frutos, tenham apresentado diferenças entre as épocas (dados não apresentados), as variações nas relações $\mathrm{Ca} / \mathrm{K}, \mathrm{Ca} / \mathrm{Mg}$ e $\mathrm{Ca} / \mathrm{P}$ foram causadas principalmente pelas alterações nos teores de Ca (Figura 8) do que pelo $\mathrm{P}, \mathrm{K}$ e $\mathrm{Mg}$ (dados não apresentados). A relação $\mathrm{Ca} / \mathrm{P}$ foi maior no mês de alta incidência da MFM (Figura 10).

Em relação ao fruto, com exceção da relação $\mathrm{Ca} / \mathrm{Mg}$, observaram-se nas folhas maiores valores das relações do Ca com os nutrientes minerais estudados. Como relatado anteriormente, esse fato foi devido às folhas terem maior taxa transpiratória (Saure, 2004), o que as mantêm com elevado teor deste nutriente.

A hipótese de que os teores baixos de Ca no fruto poderiam causar comprometimentos na estabilização da parede celular e integridade de membranas, o que facilitaria o extravasamento do látex, deve ser reavaliada. Possivelmente, os teores elevados de Ca contribuíram para maior rigidez da parede celular, facilitando assim, em caso de aumento de pressão de turgescência, o extravasamento do látex nas partes terminais dos vasos laticíferos do fruto (possivelmente associados aos estômatos). Futuros trabalhos nessa área deverão ser realizados para esclarecer tal hipótese. 

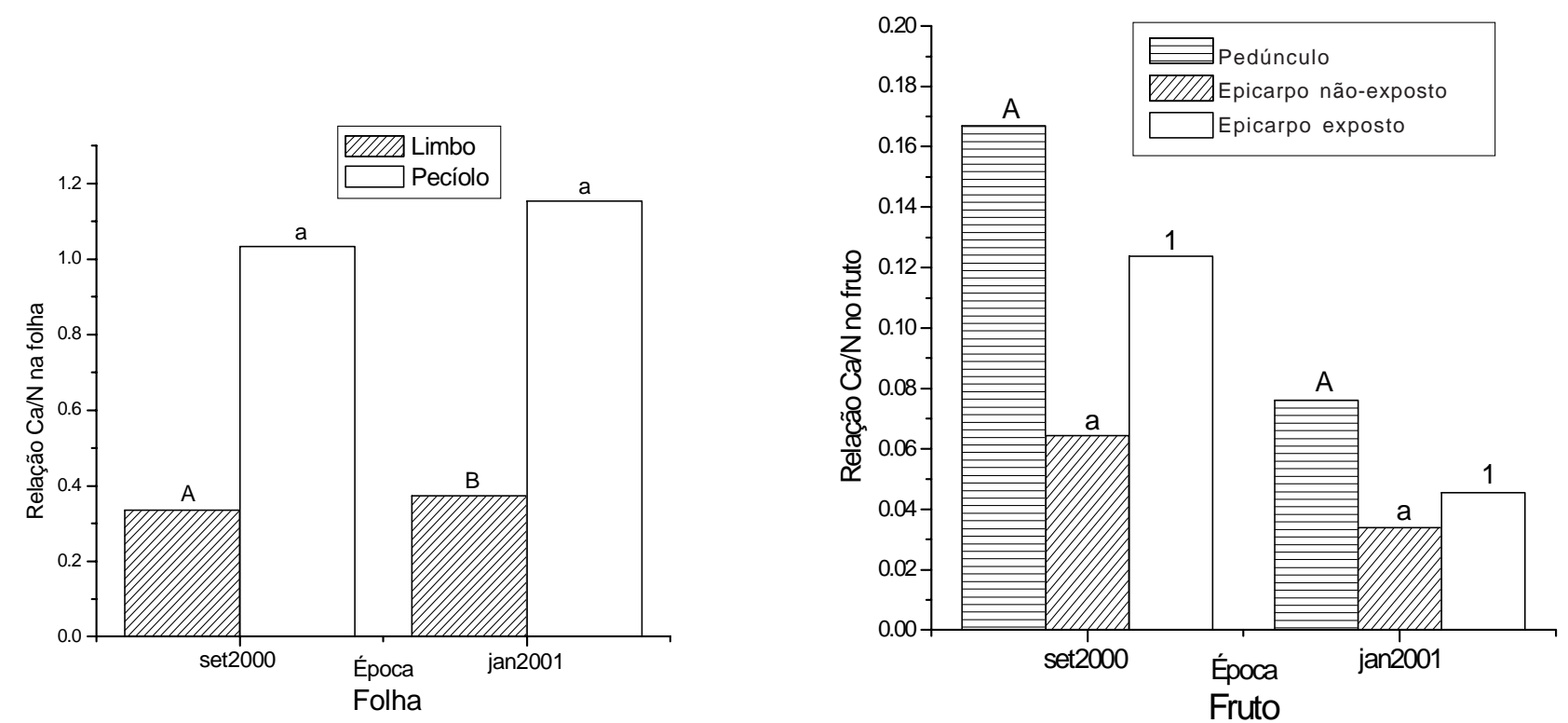

Figura 9. Relação entre o Ca/N nas folhas e nos frutos de plantas de mamoeiro cultivadas em condição de campo em duas épocas (setembro/maior incidência da MFM e janeiro/incidência nula) em São Francisco do Itabapoana, RJ. ( $\mathrm{n}=10$ plantas). Médias seguidas de mesma letra e mesmo número não diferem estatisticamente a $5 \%$ pelo teste $\mathrm{t}$. Números diferentes entre as análises do epicarpo exposto diferem estatisticamente a 5\% pelo teste t.
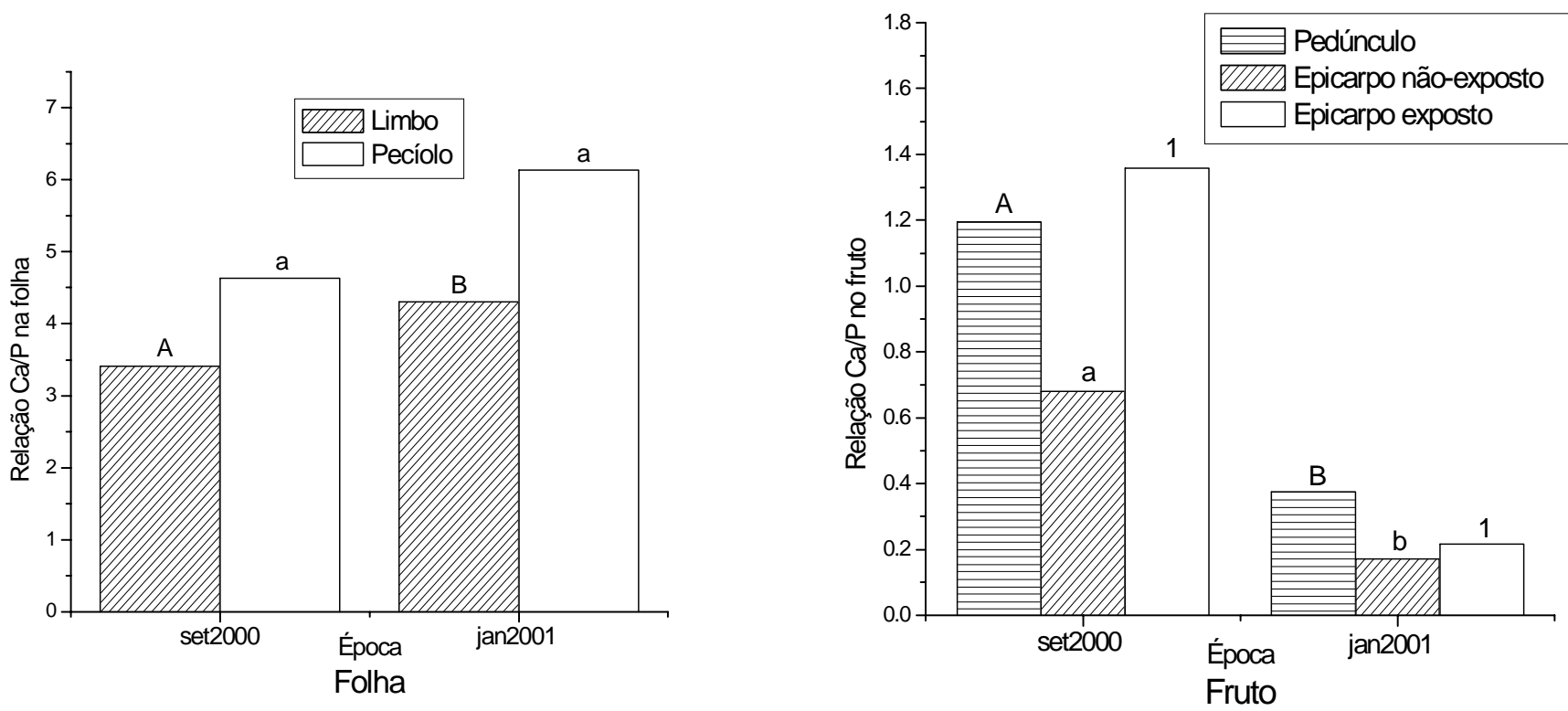

Figura 10. Relação entre $\mathrm{Ca} / \mathrm{P}$ nas folhas e nos frutos de plantas de mamoeiro cultivadas em condição de campo em duas épocas (setembro/maior incidência da MFM e janeiro/incidência nula) em São Francisco do Itabapoana, RJ. ( $n=10$ plantas). Médias seguidas de mesma letra e mesmo número não diferem estatisticamente a 5\% pelo teste $t$. Números diferentes entre as análises do epicarpo exposto diferem estatisticamente a 5\% pelo teste $t$. 

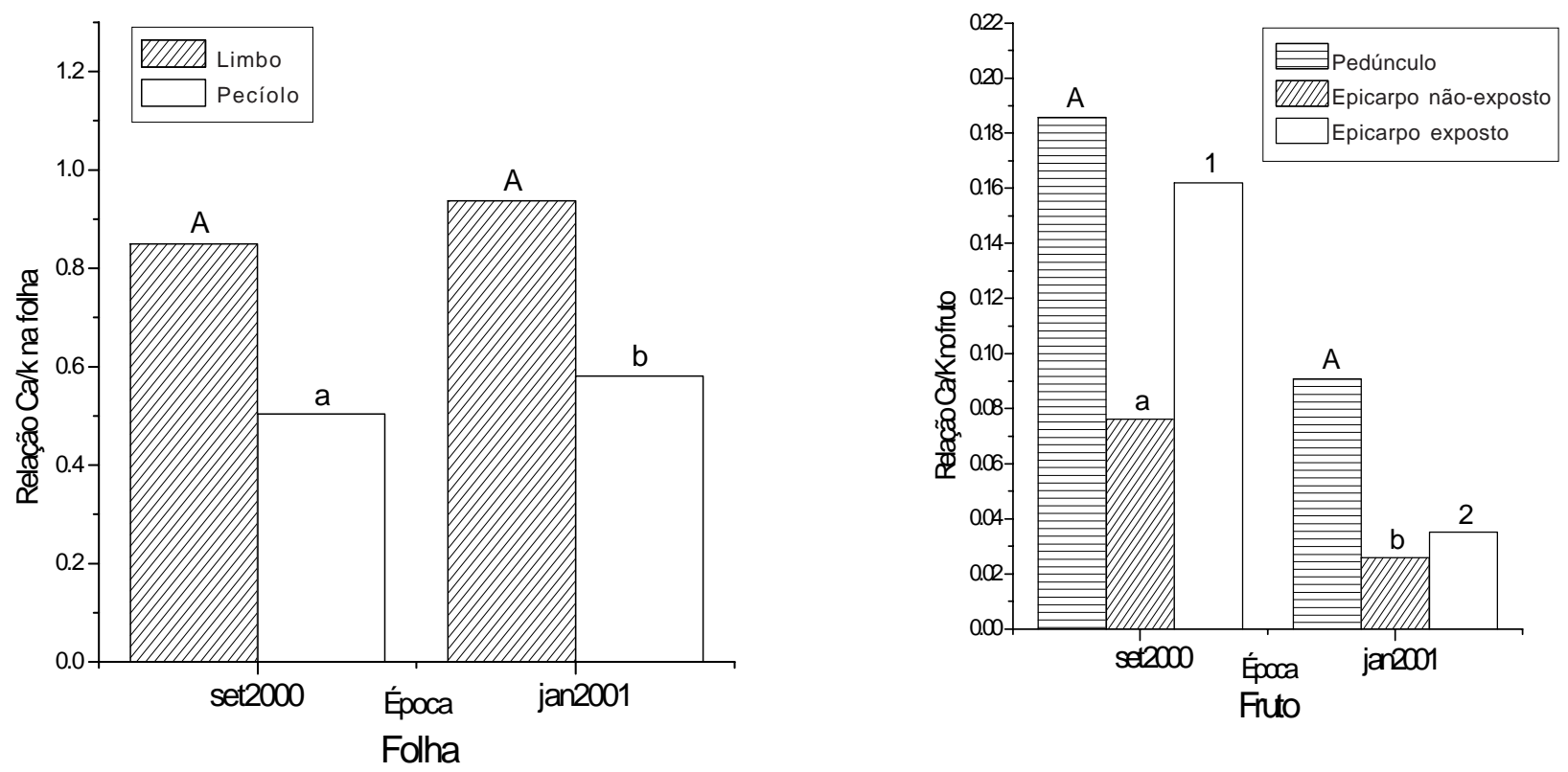

Figura 11. Relação entre $\mathrm{Ca} / \mathrm{K}$ nas folhas e nos frutos de plantas de mamoeiro cultivadas em condição de campo em duas épocas (setembro/maior incidência da MFM e janeiro/incidência nula) em São Francisco do Itabapoana, RJ. ( $\mathrm{n}=10$ plantas). Médias seguidas de mesma letra e mesmo número não diferem estatisticamente a $5 \%$ pelo teste $\mathrm{t}$. Números diferentes entre as análises do epicarpo exposto diferem estatisticamente a $5 \%$ pelo teste $t$.
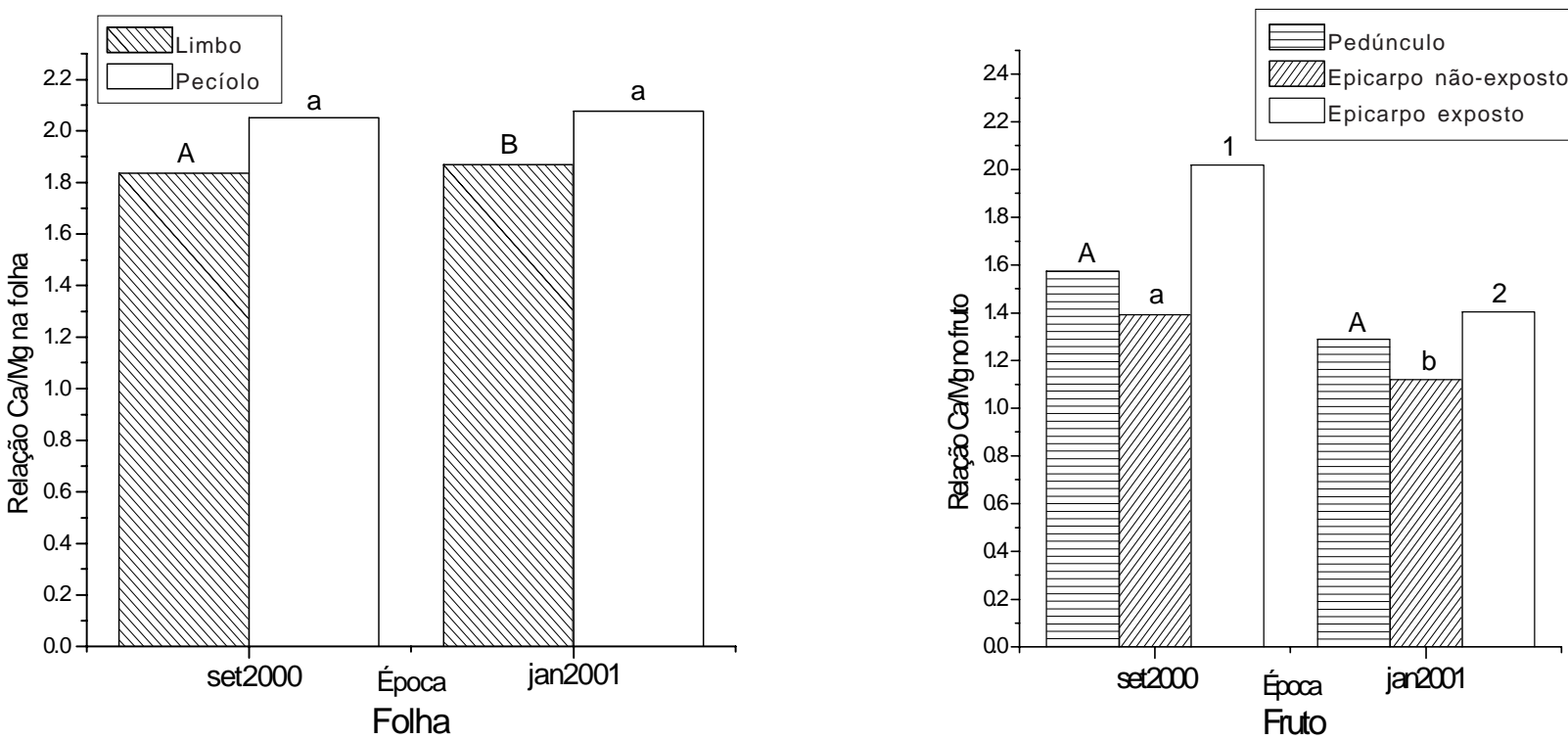

Figura 12. Relação entre $\mathrm{Ca} / \mathrm{Mg}$ nas folhas e nos frutos de plantas de mamoeiro cultivadas em condição de campo em duas épocas (setembro/maior incidência da MFM e janeiro/incidência nula) em São Francisco do Itabapoana, RJ. ( $n=10$ plantas). Médias seguidas de mesma letra e mesmo número não diferem estatisticamente a $5 \%$ pelo teste $t$. 


\section{CONCLUSÕES}

1. Em um período de estudo de um ano no Norte Fluminense, em um plantio comercial de mamoeiro do grupo 'Formosa', em setembro/2000, a incidência da mancha fisiológica do mamão atingiu o nível máximo; em janeiro a incidência foi nula.

2. Na região em estudo, as variáveis temperatura e amplitude térmica do ar, nos três meses que antecederam ao mês de maior ocorrência da MFM, mostraram-se como os fatores mais relacionados com a ocorrência deste distúrbio fisiológico.

3. Os teores de $\mathrm{Ca}$, nas partes estudadas dos frutos, foram mais elevados em setembro/2000 em relação a janeiro/2001 e as relações $\mathrm{Ca} / \mathrm{K} \mathrm{e} \mathrm{Ca/Mg}$, no epicarpo exposto e não-exposto, foram elevadas em setembro/2000 em relação a janeiro/2001.

4. A relação Ca/P no pedúnculo, no epicarpo não-exposto e no epicarpo exposto foi maior em setembro/2000 em relação a janeiro/2001.

\section{AGRADECIMENTOS}

À Fundação Carlos Chagas de Amparo à Pesquisa do Estado do Rio de Janeiro (FAPERJ) e à Financiadora de Estudos e Projetos (FINEP) pelo apoio nas pesquisas.

\section{REFERÊNCIAS}

ALONI, B., KARNI, L., RYLSKI, I., COHEN, Y., LEE, Y., FUCHS, M., MORESHET, S., YAO, C. Cuticular cracking in pepper fruit. I. Effects of night temperature and humidity. Journal Horticultural Science Biotechnology, v.73, p.743-749, 1998.

BANGERTTH, F. Calcium related physiological disords of plants. Annual Review Phytopathology, v.17, p.97-102, 1979.

BRAPEX. Associação Brasileira dos Exportadores de Papaya. Disponível em: www.brapex.net. 2004

CHAN, Y.K., TOH, W.K. Resistance to papaya fruit freckles among three breeding lines and their hybrids. Mardi Research Journal, v.16, p.103-107, 1988.

CHOI, J.H.; CHUNG, G.C.; SUH, S.R.; YU, J.A.; SUNG, J.H.; CHOI, K.J. Suppression of calcium transport to shoots by root restriction in tomato plants. Plant Cell Physiology, v.38, p.495498,1997

CLARKSON, D.T. Calcium transport between tissues and its distribution in the plant. Plant Cell Environment, v.7, p.449452, 1984.
COSTA, A.N. Uso do sistema integrado de diagnose e recomendação(DRIS), na avaliação do estado nutricional do mamoeiro (Carica papaya L.) no Estado do Espírito Santo. Viçosa/MG, 1995. 93p. Tese (Doutorado), Universidade Federal de Viçosa - UFV.

COUTINHO, K.S., CUNHA, M., OLIVEIRA, J., CAMPOSTRINI, E. (2001) Estudo anatômico de frutos de mamão que apresentam a mancha fisiológica do fruto do mamão (Carica papaya L.). Anais do Congresso Brasileiro de Fisiologia Vegetal, v.8, p.134, 2001.

COWAY, W.S., SAMS, C.E. The efects of postharvest infiltration of calcium, magnesium, or strontium on decay, firmeness, respiration and ethylene production in apples. Journal American Society for Horticultural Science, v.112, p.300-303, 1987.

CREASY, L.L. The correlation of weather parameters with russet of 'Golden Delicious' apples under orchard conditions. Journal American Society for Horticultural Science. v.105, p.735-738, 1980.

DATTA, S.K.; IQBAL, M. The laticiferous system in vascular plants. In: IQBAL, M. (ed.) Growth patterns in vascular plants. Timber Press, Portland, 1994. 137-161p.

DOWNTON, W.J.S. Water relations of laticifers in Nerium oleander. Australian Journal Plant Physiology, v.8, p.329-334, 1981.

EAKS, I.L. Effects of calcium on ripening, respiration rate, ethylene production and quality of avocado fruit. Journal American Society for Horticultural Science, v.110, p.145-148, 1985.

FINK, S. Comparative microscopical studies on the patterns of calcium oxalate distribution in the needles of various conifer species. Botanica Acta, v.104, p.306-315, 1991

FOY, C.D., WEBB, H.W., JONES, J.E. Adaptation of cotton genotypes to an acid, mangnese toxic soil. Agronomy Journal, v.73, p.107-11, 1981.

GRANGE, R.I., HAND, D.W. A review of the effects of atmospheric humidity on the growth of horticultural crops. Journal of Horticultural Science, v.62, p.125-134, 1987.

GREENE, D.W. Reduced rates and multiple sprays of paclobutrazol control growth and improve fruit quality of 'Delicious' apples. Journal American Society for Horticultural Science, v.116, 807-812, 1991.

GREENE, D.W.; LORD, W.J. Effects of dormant pruning, summer pruning, scoring, and growth regulators on growth, yield, and fruit quality of 'Delicious' and 'Cortland' apple trees. Journal American Society for Horticultural Science, v.108, p.590-595, 1983.

HINE, R.B., HOLTZMANN, O.V., RAABE, R.D. Diseases of papaya. Honolulu, HI: Hawaii Agricultural Experiment Station, 1965. p.1-26. (UH Bulletin)

HORST, W.J., MARSCHNER, H. Effect of excessive manganese supply on uptake and translocation of calcium in bean plants (Phaseolus vulgares L.). Z. Pflanzenphysiol. v.87, p.137-148, 1978. 
ISHII, M., HOLTZMANN, O.V. Papaya mosaic disease in Hawaii. Plant Disease Report, v.47, p.947-951, 1963.

JACKSON, M.L. Soil chemical analysis. New Jersey: Prentice Hall, 1958. 498p.

JONES JR., J.B., WOLF, B., MILLS, H.A. (1991) Plant analysis handbook: a pratical sampling, preparation, analysis, and interpretation guide. Athens (USA): Micro-Macro Publishing, 1991. 213p.

JONES, H.G. Plants and microclimate: a quantitative approach to environmental plant physiology. Cambridge University Press, 1992. 85p.

KAISER, C., ALLAN, P.,WHITE, B.J., DEHRMANN, F.M. Some morphological aspects of freckle on papaya (Carica papaya L.) fruit. Journal South Africa Society Science, v.6, p.37-40, 1996.

MALAVOLTA, E., VITTI, G.C., OLIVEIRA, S.A.D.E. Avaliação do estado nutricional das plantas: princípios e aplicações. Piracicaba: POTAFOS, 1989. 201p.

MARINHO, C.S. Avaliação do estado nutricional e adubação do mamoeiro (Carica papaya L.) no Norte Fluminense. 1999. 80f. Dissertação (Doutorado em Produção vegetal), Universidade Estadual do Norte Fluminense-UENF. Campos dos Goytacazes/RJ

MARSCHNER, H. Mineral nutrition of higher plants. San Diego: Academic Press, 1995. 889p.

MIX, G.P., MARSCHNER, H. Calciumgehalte in früchten von paprika, bohnen, quitte und hagebutte im verlauf des fruchtwachstums. Z. Pflanzenernähr. Bodenk, v.139, p.537549,1976

MULHOLLAND, B.J.; FUSSELL, M.; EDMONDSON, R.N.; BASHAM, J.; MCKEE, J.M.T. Effect of vpd, K nutrition and root-zone temperature on leaf area development, accumulation of $\mathrm{Ca}$ and $\mathrm{K}$ and yield tomato. Journal Horticultural Science Biotechnology, V.76, p..641-647, 2001

PAULL, R.E., CHEN, N.J. Waxing and plastic wraps influence water loss from papaya fruit during storage and ripening. Journal American Society for Horticultural Science, v.114, p.937-942, 1989.

POOVAIAH, B.W. Role of calcium and calmodulin in plant growth and development. HortScience, v.20, p.347-352, 1985.
POOVAIAH, B.W. Role of calcium in prolonging storage life of fruits and vegetables. Food Technology, v.40, p.86-89, 1986

QIU, Y., NISHINA, M.S., PAULL, R.E. Papaya fruit growth, calcium uptake, and fruit ripening. Journal American Society for Horticultural Science, v.120, p.246-253, 1995.

REUTHER, D.J., ROBINSON, J.B. Plant Analysis: An Interpretation Manual. Melbourne: Inkatan Press, 1986. 218p

REIS, F.O.; CAMPOSTRINI, E.; SOUSA, E.F.; TORRES-NETTO, A. Mancha fisiológica do mamão 'Formosa': relações com o potencial hídrico do solo, o teor de sólidos solúveis totais do látex e as variáveis do clima. In: MARTINS, D.S. (Ed.) Papaya Brasil. DCM-Incaper, Vitória, 2003, p. 421-426.

REYES, E.M.Q.; PAULL, R. E. Skin freckles on solo papaya fruit. Scientia Horticulturae, v.58, p.31-39, 1994.

RIGNEY,C.J., WILLS, R.B.H. Calcium movement, a regulating factor in the initiation of tomato fruit ripening. HortScience, v.16, p.550-551, 1981.

SAURE, M.C. Calcium translocation to fleshy fruit: its mechanism and endogenous control. Scientia Horticulturae (in press), 2005. v.105, p.65-89

SCHAFFER, B., WHILEY, A.W., CRANE J.H. Mango. In: SCHAFFER, B., ANDERSEN, P.C. (ed) Handbook of environmental physiology of fruit crops. Boca Raton: CRC Press, 1994. v.2, p.165-197

SELVARAJ, Y.; PAL, D.K.; SUBRAMANYAM, M.D.; IYER, P.A. Changes in the chemical composition of four cultivars of papaya (Carica papaya L.) during growth and development. Journal Horticultural Science, v.57,135-143, 1982.

TADESSE, T.; NICHOLS, M.A.; HEWETT, E.W.; FISHER, K.J. Relative humidity around the fruit influences the mineral composition and incidence of blossom-end rot in sweet pepper fruit. Journal Horticultural Science Biotechnology, v.76, p. 916,2001

UENO, B., NEVES, E.F., MACHADO FILHO, J.A., YAMANISHI, O.K., FAGUNDES, G.R., CAMPOSTRINI, E. (2002) Mancha fisiológica em frutos de mamoeiro no oeste da Bahia. Relatório de trabalho Universidade de Brasília / Associação dos Irrigantes do Oeste da Bahia (AIBA). Brasília-DF. 109p. 